\title{
Absorption of VFA and amino acids from the large intestine of sheep
}

\author{
B Skiba, J Kowalczyk, T Zebrowska
}

The Kielanowski Institute of Animal Physiology and Nutrition Polish Academy of Sciences, 05-110 Jablonna, Poland

Experiments were carried out on eight one year old rams of about $45 \mathrm{~kg}$, four of them supplied with cannulae into the surgically isolated caecum and four with about $1 \mathrm{~m}$ long loops of colon. The isolated segment of colon was made of the centripetal and centrifugal gyri and was equipped with two (entry and exit) cannulae which allowed perfusion. The isolated caecum was filled and loop of colon were perfused with amino acids solution of three different concentrations $(0.1,0.15$ and $0.3 \mathrm{mg}$ $A A / 100 \mathrm{ml}$ ) or VFA solutions of two different concentrations (50 and $100 \mathrm{mM} / \mathrm{l}$ ) containing $P E G$ as a indicator. The content of individual $A A$ or VFA were measured in the solution emptied from the caecum and in the perfusate from the colon. Each treatment was repeated five times. The animals were fed meadow hay and barley grain.

The amount of acetate, propionate and butyrate in the perfusate from the caecum and colon decreased with time at both concentrations of VFA in the infusate. After period of $4 \mathrm{~h}$ the acetate was absorbed from the caecum in $42 \%$ $(2.7 \mathrm{mM})$ and $58 \%(6.9 \mathrm{mM})$ from the infusate containing 50 and $100 \mathrm{mM} / \mathrm{I}$ VFA, respectively. The amount of acetate absorbed from the colon increased from 10.8 to $18.8 \mathrm{mM}(P \leq 0.05)$ with increasing VFA concentration but the rate of its absorption decreased from $30 \%$ to $25.6 \%$ The intensity of the propionate (65-68\%) and butyrate $(77 \%)$ absorption from the caecum was larger than for acetate (42\%), independing on VFA concentration although for butyrate it was slightly decreasing to $66 \%$ with increasing concentration of VFA. The rate of these VFA absorption from the colon was smaller than from the caecum but it also decreased with its concentration.

From among a mixture of 16 amino acids only Thr (48-73\%), Ser (30-52\%), Asp (40\%) and Arg $(31 \%)$ were absorbed from the caecum in significant proportion $(\mathrm{P} \leq 0.01 ; \mathrm{P} \leq 0.01$; $P \leq 0.01 ; P \leq 0.05$, respectively) and the rate of absorption varied with the concentration of amino acids in the infusate.

$\begin{array}{lccc}\text { Indices } & \text { acetate } & \text { propionate } & \text { butyrate } \\ \overline{\text { VFA concentration } 50 \mathrm{mM}} & & & \\ \text { Amount introduced }(\mathrm{mM}) & 5.8^{\mathrm{a}} & 2.3^{\mathrm{a}} & 1.3^{\mathrm{a}} \\ \text { Amount collected }(\mathrm{mM}) & 3.4^{\mathrm{b}} & 0.8^{\mathrm{a}} & 0.3^{\mathrm{a}} \\ \text { Absorption }(\%) & 42 & 65 & 77 \\ V F A \text { concentration } 100 \mathrm{mM} & & & \\ \text { Amount introduced }(\mathrm{mM}) & 12.1^{\mathrm{A}} & 5.0^{\mathrm{a}} & 3.0^{\mathrm{a}} \\ \text { Amount collected }(\mathrm{mM}) & 5.1^{\mathrm{B}} & 1.6^{\mathrm{b}} & 1.0^{\mathrm{a}} \\ \text { Absorption }(\%) & 58 & 68 & 66 \\ \text { a,b }: \mathrm{P} \leq 0.05 ; \mathrm{A}, \mathrm{B}: \mathrm{P} \leq 0.01 & & & \end{array}$

